\title{
OBSERVATIONS ON SEASONAL DYNAMICS OF AGE STRUCTURE AND REPRODUCTION OF PUPILLA MUSCORUM L. (GASTROPODA: PULMONATA: PUPILLIDAE)
}

\author{
BEATA M. POKRYSZKO
}

\begin{abstract}
Museum of Natural History, Wrocław University, Sienkiewicza 21, 50-335 Wrocław, Poland (e-mail: bepok@culex.biol.uni.wroc.pl)

ABSTRACT: Ovoviviparous Pupilla muscorum L. incubates 1-8 embryos throughout the year. The embryos are produced in an assembly-line fashion and released when fully formed, with a maximum in June-August. The snails reach maturity in their second or third season and probably most reproduce only during one season.
\end{abstract}

KEY WORDS: ovoviviparity, terrestrial pulmonates, Pupilla muscorum, reproduction

\section{INTRODUCTION}

Most of what is known of reproduction in pupilloids are scattered facts resulting from sporadical observations (e.g. STEENBERG 1925, FRÖMMING 1954, POKRYSZKO 1990a). The only more comprehensive accounts of pupilloid life histories are those by POKRYSZKo (1990b) and HELlER et al. (1997), dealing with Vertigo pusilla O. F. Müller (Vertiginidae) and Lauria cylindracea (Da Costa) (Pupillidae), respectively. The latter species is the

\section{MATERIAL AND METHODS}

In order to estimate the number of incubated embryos and the degree of their development, samples of adult Pupilla muscorum L. were taken monthly, from March till October 1998 from castle ruins in the town of Wleń near Jelenia Góra, SW Poland. The total number of adults obtained from the Wlen population and examined anatomically was 328, the monthly samples ranging from 33 snails in September to 56 in May. From November 1998 till February 1999 weather prevented me from collecting a sufficient number of live, adult snails; only at the end of November and at the beginning of February 10 and 8 individuals were only thoroughly studied ovoviviparous pulmonate. Since evolution of snail ovoviviparity is by no means clear, mainly because so very little is known of members of the ovoviviparous guild (cf. TOMPA 1979a, b, 1984, BAUR 1994, Heller et al. 1997, POKRYSZKo 1998 and in prep.), it is worthwhile to publish any observations on their life histories. This paper provides at least some data on the reproduction of Pupilla muscorum L. collected, respectively. The snails were drowned in boiled, lukewarm water and preserved in $75 \%$ ethanol. Besides, the following alcohol-preserved materials from the collections of the Museum of Natural History, Wrocław University (MPWr) and the Museum and Institute of Zoology, Polish Academy of Sciences, Warsaw (MiIZPAN) were examined for the number and degree of development of incubated embryos: Bochotnica nr. Kazimierz nad Wisłą, CE Poland, 17 October 1950 (97 specimens) and 9 July 1951 (19 specimens), A. RIEDEL, MiIZPAN; Kazimierz nad Wisłą, CE Poland, 16 October 1950 (83 specimens) 

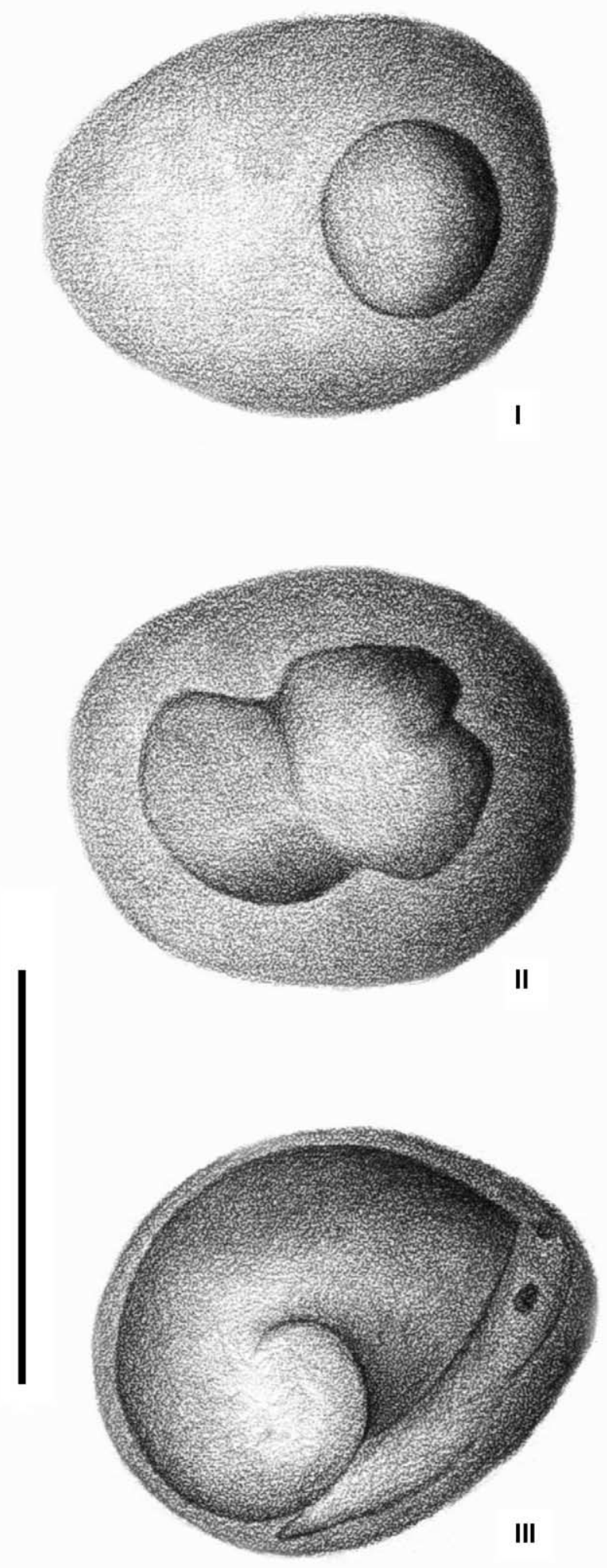

Fig. 1. Three development stages of embryos of Pupilla muscorum. Scale bar $1 \mathrm{~mm}$ and 6-19 July 1951 (37 specimens), A. RIEDEL, MiIZPAN; Nałęczów nr. Puławy, CE Poland, 13 July 1951, A. RiEDEL, MiIZPAN, 8 specimens; Krzyżanowice nr. Pińczów, S Poland, 29 August 1956, B. BurAKOWSKI, MiIZPAN, 27 specimens; Serock nr. Pułtusk, NE Poland, 6 March 1953, R. BIELAWSKI, MiIZPAN, 56 specimens; Podlesice nr. Zawiercie, S Poland, 13 July 1980, B. M. POKRYSZKO, MPWr, 33 specimens; Stary Folwark nr. Suwałki, NE Poland, $21 \mathrm{Au}-$ gust 1981, B. M. POKRYSZKO, MPWr, 41 specimens; Guzy nr. Kowale Oleckie, NE Poland, 24 August 1981, B. M. POKRYSZKo, MPWr, 23 specimens; Ręboszewo nr. Kartuzy, CN Poland, 2 July 1982, B. M. POKRYSzKO, MPWr, 10 specimens.

Each alcohol-preserved adult was dissected, the embryos removed, counted and their development stage estimated, considering their position in the spermoviduct. Three stages of the development of the embryos were distinguished (Fig. 1): I - milky white, spherical or slightly oval, pigmentless embryo occupying not more than 1/4 egg diameter; II - irregular, pigmentless embryo with visible rudiments of head, visceral sac and podocyst, occupying more than $1 / 4$ and most often 1/3-3/4 egg diameter; III - embryo with coiled visceral sac, pigmented ommatophores, and developed or still undeveloped shell, occupying almost whole egg diameter. Besides, the male genitalia of each adult were classified as reduced (penis, epiphallus and penial appendix thread-like, of a thickness similar to that of vas deferens) or normally developed.

Four samples were taken in April, June, August and October 1998 from the same locality, in order to estimate the age structure: each sample, of ca. 21 litter and debris, was sifted through an entomological sieve of $5 \times 5$ mesh and scanned for live Pupilla. From 110 (August) to 430 (October) snails were obtained on each control. Whorls were counted according to EHRMANN (1933) and each individual was assigned to one of the following age classes: I (newborn young) 1-2 whorls, II - 2.1-3 whorls; III - 3.1-4 whorls, IV 4.1-5 whorls, V - 5.1-6 whorls and VI (adults) -6 plus whorls, lip completed.

\section{RESULTS}

In each of the examined samples a majority (up to $100 \%$ ) of adults were gravid. The spermoviduct filled with the incubated embryos occupied from 0.75 to 1.5 whorl of the visceral sac. The number of incubated embryos in the population from Wleń ranged from 1 to 8 , with most individuals containing 2-6 embryos (two adults from the population in Stary Folwark near Suwałki contained 9 and 10 embryos, respectively). Only a low proportion of individuals had in their gonoducts embryos at one development stage, and in 


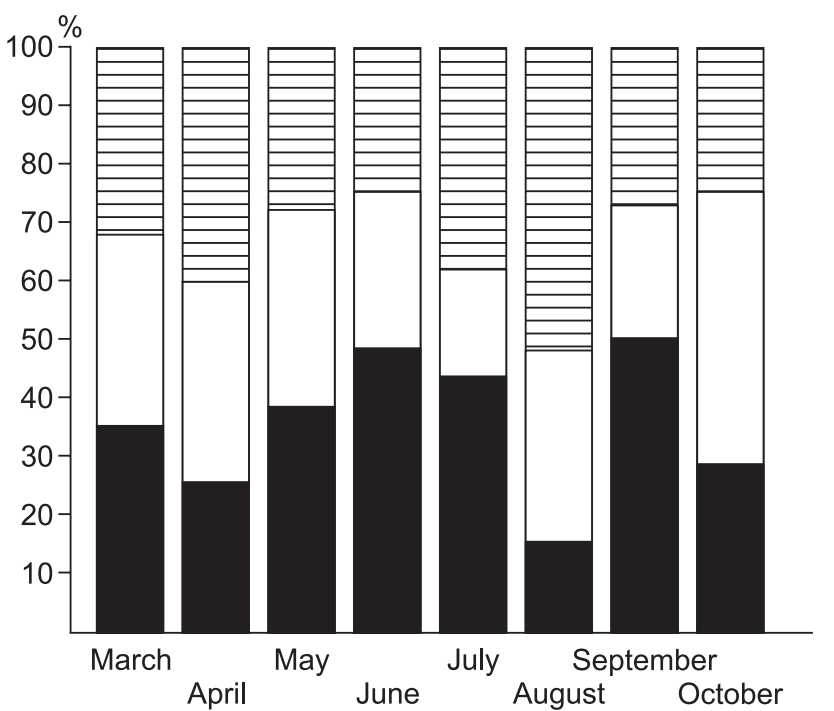

Fig. 2. Degree of advancement of development of embryos incubated by Pupilla muscorum from Wleń nr. Jelenia Góra. Stage I - black, II - white, III - hatched

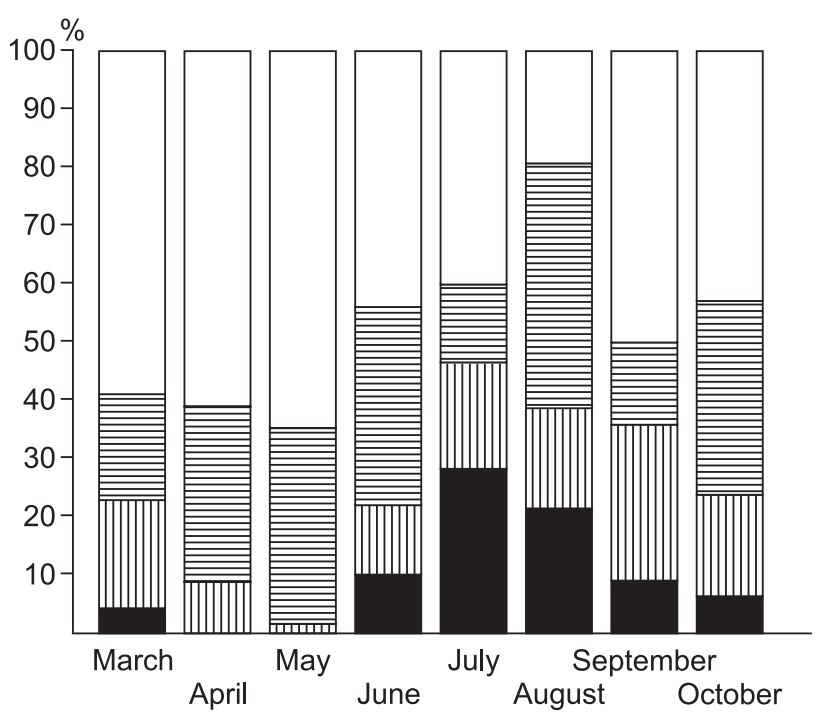

Fig. 4. Percentage of adult Pupilla muscorum: non-gravid (black) and gravid, containing embryos at one (vertical hatching), two (horizontal hatching) and three (white) development stages. Population from Wleń nr. Jelenia Góra

these cases the number of embryos was 1-2, only exceptionally (3 out of 62 such individuals) -3 ; in individuals with embryos at two development stages (I \& II, I \& III or II \& III) the number of embryos was 2-3, only in very few cases (5 out of 120 such individuals) -4 . When the number of embryos ranged from 4 to 8 , they nearly always (169 out of 174 such cases) represented stages I, II and III. The same pertained to the few individuals collected in November and February, though the variation was smaller for obvious reasons. The embryos were always linearly arranged, the most advanced being located the closest to the gonopore and the least advanced the closest to the albumen gland.

The degree of advancement of development of the incubated embryos in the population from Wlen is pre-

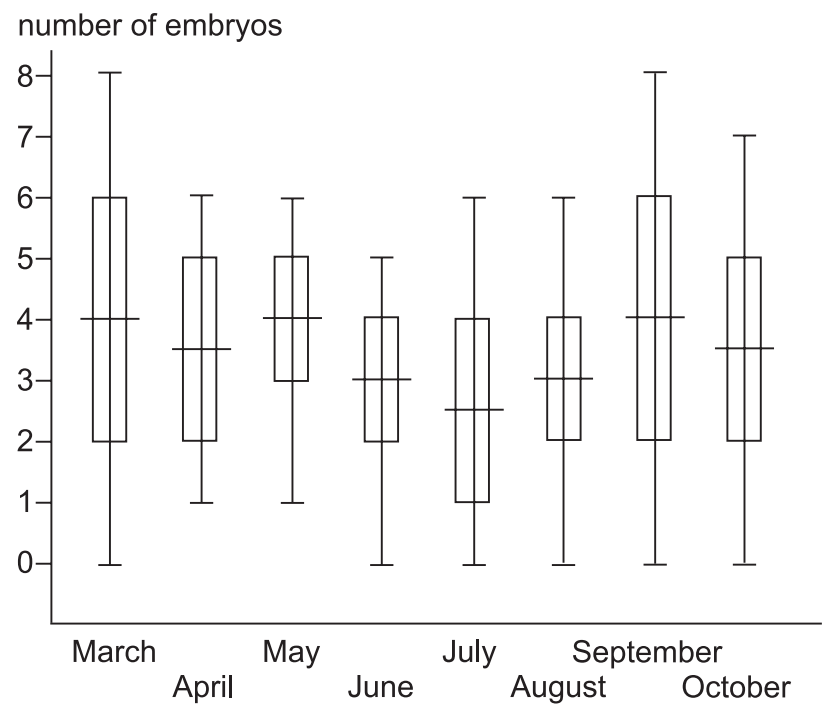

Fig. 3. Number of embryos incubated by Pupilla muscorum from Wleń nr. Jelenia Góra: range, mean and SD

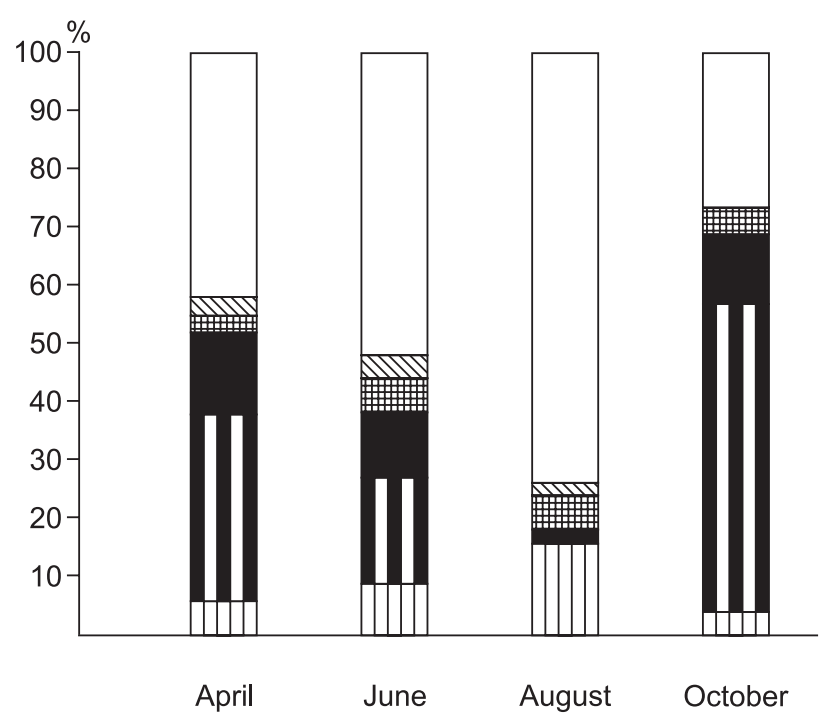

Fig. 5. Age structure of population of Pupilla muscorum from Wleń nr. Jelenia Góra: class I - vertical hatching, II striped, III - black, IV - cross-hatching, V - oblique hatching, VI - white

sented in Figure 2. All the stages were represented in all the samples, though their proportion showed some fluctuations, with the percentage of stage I embryos decreasing gradually in June, July and August, and then increasing again in September, the increase being followed be an increase in the proportion of stage II and III embryos. The mean number of incubated embryos displayed some variation among the samples, with a minimum in June, July and August (Fig. 3). The proportion of adults containing embryos at various development stages varied, with individuals containing embryos at all stages becoming less frequent in June, July and August, while the percentage of non-gravid adults reached its peak in July (Fig. 4). The situation observed in the occasional samples from other localities 
did not depart from that presented in the graphs in Figures 2-4 for the respective months.

All the gravid individuals had their male genitalia reduced to thread-like structures. About $50 \%$ (42 out of the total of 86) dissected non-gravid adults had their male genitalia fully developed; in the remaining individuals the male parts were thread-like.

The age structure of the population (Fig. 5) varied considerably between the samples. The proportion of all the immature individuals pooled together (classes I-V in Fig. 5), as well as of each of classes II-V decreased from April to August, and then, except class $\mathrm{V}$, increased considerably till October. The proportion of newborn snails (class I in Fig. 5) increased from c. $5 \%$ in April to nearly $20 \%$ in June-August, to decrease to less than $5 \%$ in October. The percentage of adults increased from April till August and then decreased considerably till October.

\section{DISCUSSION}

The results allow a reconstruction of some traits of the reproductive cycle of Pupilla muscorum. The embryos are produced in an assembly-line fashion, the most advanced and closest to the gonopore being gradually born and new ones being added at the other end of the spermoviduct. This is reflected also in Figures 2-5. The high percentage of stage III embryos in March and April and the high mean number of incubated embryos in these two months (Figs 2 and 3 , respectively) correspond to the low percentage of newborn snails in the population in April (Fig. 5). The decrease in the mean number of incubated embryos in June-August (Fig. 3) is accompanied by an increased proportion of non-gravid adults (Fig. 4) and of newborn individuals in these months (Fig. 5). Though the high percentage of non-gravid adults does not necessarily imply that all of them have just released their embryos (see below), it appears that the peak of releasing young falls on June-August (cf. proportion of newborn young in Fig. 5), and the reproduction becomes less intense in the autumn: in October the embryos are still produced and incubated but only few are actually born (cf. increase in the mean number of incubated embryos in September in Fig. 3 and decreased proportion of newborn snails and non-gravid adults in the population in October in Figs 4 and 5). The few dissected adults collected in November and February, all of them containing embryos, indicate that adult $P$. muscorum are gravid throughout winter which is in agreement with FRÖMMING's (1954) data.

The non-gravid adults may represent one of the three categories: 1 . individuals that have released their embryos and have not yet produced new embryos, 2. individuals that have just reached maturity and have not yet started producing embryos, or 3. individuals that have finished their reproduction and will die soon.

Since with the release of stage III young, new embryos are gradually added at the albumen gland end of the spermoviduct, situations with no embryos in the gonoducts are not likely to happen during reproduction, unless the development and release of em- bryos during the summer reproduction peak (cf. Figs 4,5 ) are much quicker than production of new embryos. Thus possibility 1 is unlikely but not excluded. The proportion of non-gravid adults with their male parts fully-developed to thread-like (ca. 1:1) may indicate that two situations are represented among the non-gravid snails. The snails with fully-developed male parts may be those that have reached maturity but still not started to reproduce (possibility 2) while those with thread-like male genitalia may have completed their reproduction and will die soon (possibility 3). The situation is complicated by the lack of data on cross-breeding versus uniparental reproduction in Pupilla, and on the relation between the reproduction and the degree of development of the male parts. The reproduction may be biparental or uniparental, or alternatingly uni- and biparental, all the situations being known in terrestrial pulmonates (cf. TOMPA 1984, BAUR 1989, POKRYSZKO 1990b, KUŹNIK-KOWALSKA 1999). It is unknown if the reduction of the male genitalia to thread-like structures in gravid Pupilla is reversible, but most probably their appearance has to do with the ability to copulate. It is unknown whether the copulation (if any) takes place once only, or perhaps the mating is repeated.

The only other ovoviviparous pupillid with known reproductive cycle is Lauria cylindracea (Da Costa) (HELLER et al. 1997). HELLER's et al. (1997) study, in some respects much more detailed than my observations, covered 12 months and included histological examination of the gonads. In spite of this and despite the slightly different approach of these authors, some comparisons can be made. HELLER et al. (1997) found no embryos in Lauria from November till January, and in October over $50 \%$ adults were non-gravid. The degree of development of the embryos was also different from what was observed in P. muscorum, even considering the fact that HELLER at al. (1997) distinguished only two classes of embryos: the proportion of snails containing only well-developed embryos, high in August and September, decreased to zero in November, December and January when none of the adults was gravid; in February the relatively few gravid 
adults contained either undeveloped embryos or a mixture of well-developed and undeveloped embryos, the proportion of gravid adults and of adults containing only fully-developed embryos increasing gradually till July. In contrast to $P$. muscorum in which a considerable proportion of adults contained embryos of at least two development stages (cf. Fig. 4), Lauria containing embryos at various development stages appeared only from May to July and always constituted only a fraction of the adults (cf. graph in Fig. 5 in HELLER et al. 1997). In those few individuals, like in $P$. muscorum, the embryos were arranged from the least developed near the albumen gland to the most developed near the gonopore.

The maximum number of incubated embryos reported by HELLER et al. (1997) for Lauria cylindracea was six; the mean number ranged from 0.03 in February to 3.9 in July; the respective numbers in Pupilla were 10 ( 8 in the population from Wleń), 2.5 (July) and 4.5 (September).

Although in gravid Lauria the male parts may have a thread-like appearance (own, unpublished results), HELLER et al. (1997) state only that they have observed no aphallism, and do not comment on any possible differences between the gravid and non-gravid individuals.

The proportion of adult $P$. muscorum increases from the early spring till summer, in spite of the summer peak of reproductive activity (cf. Fig. 5: newborn young). The immature individuals that constitute a high percentage in the early spring, when the release of the embryos has just started (cf. all immature classes and newborn snails in April in Fig. 5), may be snails born in the previous summer and probably also two years earlier; their growth accounts for the increasing proportion of adults till August. The fact that the oldest of immature individuals (class V in Fig. 5) disappear completely in October and display a very low frequency already in August, indicates that they

\section{REFERENCES}

BAUR B. 1989. Growth and reproduction of the minute land snail Punctum pygmaeum (Draparnaud). J. Moll. Stud. 55: 383-387.

BAUR B. 1994. Parental care in terrestrial gastropods. Experientia 50: 5-14.

EHRMAnn P. 1933. Mollusca (Weichtiere). Die Tierwelt Mitteleuropas 2, 1. Leipzig.

FRÖMMING E. 1954. Biologie der mitteleuropäischen Landgastropoden. Berlin.

Heller J., Sivan N., Hodgson A. N. 1997. Reproductive biology and population dynamics of an ovoviviparous land snail, Lauria cylindracea (Pupillidae). J. Zool. London 243: 263-280. have become adult. Class II, with its high frequency in October, most probably represents individuals born in July and August. The rather drastical reduction of the mature age class between August and October may result from death of a part of the adults that have completed reproduction rather than from addition of new juveniles, since at that time of year the release of embryos has already passed its maximum (cf. August and October in Fig. 5). It is thus likely that $P$. muscorum reaches maturity in the third season of its life and that most individuals reproduce only during one season. According to HELLER et al. (1997) Lauria cylindracea matures in the third season of its life at the earliest, starts reproducing when at least 2.5 years old and may live as adult for at least 1.5 year.

Though members of one family, Lauria cylindracea and Pupilla muscorum differ markedly in their life cycle pattern, the general difference being a less pronounced seasonality of reproduction in the latter species. Combined with the completely different life history of another pupilloid - an oviparous Vertigo pusilla (POKRYSZKO 1990b) - this indicates a necessity of more detailed studies on the reproductive modes of further members of the superfamily, especially considering its crucial importance for the evolution of stylommatophoran snails (POKRYSZKO 1994). Likewise, in spite of important contributions by TOMPA (1979a, b), BAUR (1994) and HELLER et al. (1997) gastropod ovoviviparity itself, its evolution, advantages and disadvantages, require a new insight which will be presented elsewhere (POKRYSZKO in prep.)

\section{ACKNOWLEDGEMENTS}

The study was partly sponsored by the State Committee for Scientific Research, grant number 6 P04C 034 14. I am grateful to Prof. dr. hab. ANDRZEJ WIKTOR for his critical comments on the draft of this paper.

KUŹNIK-KOWALSKA E. 1999. Life cycle and population dynamics of Discus rotundatus (O. F. Müller, 1774) (Gastropoda: Pulmonata: Endodontidae). Folia Malacol. 7: 5-18.

PokryszKo B. M. 1990a. The Vertiginidae of Poland (Gastropoda: Pulmonata: Pupilloidea) - a systematic monograph. Ann. Zool. 43: 133-257.

POKRYSZKO B. M. 1990b. Life history and population dynamics of Vertigo pusilla O. F. Müller, 1774 (Gastropoda: Pulmonata: Vertiginidae), with some notes on shell and genital variability. Ann. Zool. 43: 407-432.

POKRYSZKo B. M. 1994. On the mono(?) phyly and classification of the Orthurethra/Pupilloidea (Gastropoda: Pulmonata: Stylommatophora). Genus 5: 371-390. 
POKRYSZKO B. M. 1998. Is ovoviviparity rightly advertised? Abstracts. World Congress of Malacology, Washington, D. C.: 265.

STEENBERG C. M. 1925. Études sur l'anatomie et la systematique des maillots (Fam. Pupillidae s. lat.). Copenhagen.

TOMPA A. 1979a. The systematic distribution of egg retention in the subclass Pulmonata. Aust. J. Malac. 4: 113-120.

TOMPA A. 1979b. Oviparity, egg retention and ovoviviparity in pulmonates. J. Moll. Stud. 45: 155-160.
TOMPA A. 1984. Land snails (Stylommatophora). In: The Mollusca 7. Reproduction (TOMPA A., VERDONK N. H., VAN DER BIGGELAAR J. A. M., eds): pp. 47-140, Academic Press, New York.

received: December 10th, 2000 accepted: January 5th, 2001 